\title{
EARTHQUAKES AND WINDSTORM - NATURAL DISASTERS
}

\author{
J. M. RYder, AND D. J. KIMBER
}

Earthquakes and Windstorm can range in size from small easily insurable instances up to full scale Natural Disasters. This note is particularly concerned with the problem of forecasting, rating and insuring earthquakes and windstorm at the natural disaster end of this scale.

\section{The Secret of Success in Insurance}

Before we tackle the peculiar problems of natural disaster insurance it is worth having a look at why insurance works so well in practice.

Is it because actuaries and statisticians have precisely measured the statistical risks involved, and have developed a detailed and complex mathematical approach to insurance, a true "Technical Basis" for Insurance? Or is it really quite simple?

A quotation (the first of many) from R. Heller [I] is relevant. "The great and fabled business empires with hardly an exception were built . . on irresistable ideas of elemental simplicity."

Insurance is one of these great empires, and some of the simple ideas which may explain why insurance works so well are suggested below.

\section{Some Simple Ideas}

I. "Charge far too much if you can-Worry about equity later', This is the secret of success in participating life insurance. With a large enough bonus loading you can't go wrong even if you try. [2] 2. "You can survive inadequate premiums so long as you leave yourself a loophole, and can increase premiums to recover losses"

This is the ultimate secret of insurance. Do not guarantee too much; leave yourself a loophole like not guaranteeing future 
premiums or surrender values etc. (Even life insurance companies can fail if surrender values are guaranteed at too high a level).

And remember that you can only increase premiums if you are not too far behind your competitors experience. (This is one of the major reasons for reinsurance).

3. "Insurance theory is a theory of adaptive control, not of risk"

Don't let your concern with statistical variation dominate your interest in the parameters of the insurance process. And keep your statistical theory simple.[3]

"Management theory is obsessed with risks. Theorists teach how to construct decision trees ... and how to marry the trees with probability theory. But the measuring is spurious and anyway the best management doesn't take risks. It avoids them". [4]

\section{4. "Keep it Simple"}

"If you need sophisticated calculations to justify an action it is probably wrong-and anyway the sophisticated calculations are all too often based on simple false assumptions". [I]

You should be able to control any process with "calculations which can be done on the back of an envelope". (This is part of the original definition of Systems Analysis as given by Blackett, the creator of Operations Research).

\section{5. "You can't Predict the Future-so Stop Trying To"}

You must face the blunt fact that it is not possible to predict the future and that you will often be wrong. Even the most perfect time series forecasting method will fail on a significant number of important occasions. [4]

Instead of predicting the future you must develop robust methods which can cope with almost any change in the future.

\section{6. "Prove you are Right"}

"Technical experts are always wrong until they prove themselves to be right". [I]

This is the supreme simple actuaries idea. We must demonstrate conclusively (with a Model Office study) that our methods will work in a wide range of possible futures. 
How do These Simple Ideas Apply to Natural Disasters?

The most serious problem with Natural Disaster Insurance is that you are very likely to be violating the "ultimate" simple secret of insurance-i.e. you may not be able to recover past losses in the event of a major disaster, and you may find yourself in a difficult competitive position with insurers who have avoided this particular disaster, or with new insurers.

Sharing the risk with your competitors by reinsurance reduces the threat from existing insurers. However the only protection against new insurers is the time (and cost) involved in setting up an organisation and obtaining a share of the market. The 'damaged' insurer has a few years to restore his fortunes, but not much longer.

If you can stop new insurers entering the field, by (say) a State monopoly or a legal device, you avoid this threat, and you can attempt to recover your losses by increasing premiums. This is fine if insurance is compulsory, but if it is voluntary you may find that your premiums are too high and that people underinsure or drop out completely. It may take a long while torecover past losses, and could be unfair to the (few) people who remain insured.

Natural Disaster insurance is a reasonable proposition if it is monopolistic and compulsory. It has problems if it is voluntary insurance, and the problems become more serious if there is a possibility of new insurers entering the field.

Natural Disaster insurance may be a reasonable proposition, but there is a problem in calculating reasonable premiums. When you start analysing the statistics for natural disasters you will soon realise that you are likely to be violating the third simple idea-i.e. you may be concentrating on measuring the statistical risk in a situation where the "measuring is spurious" and the concept of Risk Theory is inappropriate. This appears to be the case when you are trying to measure the probability of a very rare event.

\section{The Probability of a Rare Event}

Bayesians claim that it is nonsense to assume absolutely stable parameters (of probability distributions) over time, and they prefer to assume that they vary over time-in accordance with a stable probability law (?). 
A more reasonable approach is to simply assume that the parameter is a function of time, but to make no assumption about the form of this function.

H. Seal [5] has shown that (for example) a Poisson distribution with a varying parameter is still a Poisson distribution, but of course the probability for a subsequent time period may be quite different to the initial time period-it is not invariant.

Similarly B. Almer [6] has shown that a large heterogeneous portfolio will behave like a homogeneous portfolio, with a probability of a claim equal to the average probability. This average probability may be denoted by $\mathrm{P}_{j}$ (for the $\mathrm{jth}$ year).

This is not a simple stochastic process because the parameters $\mathrm{P}_{j}$ will vary over time. When the number of risks is large we can make the familiar naive non-verifiable hypothesis "that frequencies will remain constant and so permit extrapolation". In practice we find that frequencies bounce around far more than can be explained by statistical variation, thereby pointing up the error of our hypothesis. We cope with this situation by designing robust control methods, which can cope with the inaccuracy of our forecasting method.

When the number of risks is small and the sequence of values $P_{j}$ vary widely with time it is no longer reasonable to make this assumption that frequencies will remain constant. Natural disasters come in this category. When they are big enough and rare enough statistical measurement becomes spurious. It may be possible to use statistical theory to estimate past parameters, but that doesn's help to predict the future.

\section{A Theoretical Premium Formula}

A theoretical premium formula which has been suggested [I] for earthquake insurance is

$$
\begin{aligned}
\mathrm{P} \% \text { Sum Insured }=\text { Io. } \sum_{i=1}^{i} & {\left[\frac{\text { Expected Loss }}{\text { Sum Insured }} \times \frac{\text { Ioo }}{\text { Return Period }}\right]_{i} } \\
+ & {\left[\alpha_{1} \sigma+\alpha_{2} \sigma^{2}\right] } \\
& \text { fluctuation loading. }
\end{aligned}
$$

The return period is the average number of years between 
accidents. $i=1,7$ rates the earthquakes by severity. $\sigma$ is the standard deviation in \% of sum insured.

It is more than likely that the measurement of the very rare very large categories (Return Period $\geq 50$ ) is spurious-which in turn makes the fluctuation loading spurious. We seem to have here a perfect example of sophisticated calculations based on simple false assumptions.

Basically the premium to be charged for a very rare very large risk is a "stab in the dark". We can of course use the premium formula above, but we should not place any reliance on it, and we should not bamboozle ourselves with statistical science into thinking the standard deviation has much meaning.

\section{Proposals for a Natural Disaster Insurance Scheme}

An article in the General Insurance Bulletin [8] makes the following points in connection with a proposal for a natural disaster insurance scheme.

(a) Cover should be universal, not voluntary.

(b) Premiums should be collected in part from a loading on insurance premiums (fire, property etc.), with inter-regional subsidies to equalise premiums as far as possible.

Premiums should also be levied through rates on property, so that all property owners contribute to the cost, and not just the careful owners who insure. These premiums would be used for small frequently occurring disasters. It was not intended to build up a major fund sufficient to cover a really serious disaster (such as the destruction of a major city)-since the funds built up were "white anted" by inflation, possible illiquid, and themselves at risk from disasters. In addition the premium level sufficient to build up such a fund could well be unacceptably high. (A high premium can only be justified retrospectively).

(c) It was strongly recommended that major disaster should be regarded as a charge on the country as a whole, and that the cost should be spread amongst people as equitably as possible, i.e. by increased income taxation etc., after the event.

(d) A relief organization should be set up to move promptly to the 
assistance of a disaster area. In the short run this was more important than monetary compensation.

(e) The development of disaster prone areas should be discouraged etc.

\section{An Alternative Proposal}

An alternative proposal is currently a matter of public discussion. This proposal includes the following points:-

(i) Cover would be voluntary (Compulsion would be considered if necessary.)

(ii) Premiums would be set (by an Advisory Committee) taking into account risk differences.

(iii) Cover would be provided by a Pool of general insurers which would meet claims from their own resources.

(iv) Reinsurance facilities would be offered by the Government up to a specified maximum limit. These reinsurance arrangements would be developed in accordance with sound insurance principles, subject to the requirement of producing acceptable levels of premiums to the public.

(v) The Pool would reinsure the excess over the Government limit, subject to availability and cost.

(vi) If all these insurance arrangements failed to meet claims it would be regarded as a national emergency, and Government assistance would be provided "on an ad hoc basis, tailored to meet the prevailing conditions". The level of this assistance would depend on "considerations of economic management, allocation of national resources, and relative needs".

\section{Possible Criticisms}

This alternative proposal is workable, but it is open to a number of criticisms, e.g.

(a) What happens to people who are not insured?

(b) Why should careful people who insure their property in a low risk area pay for claims in a high risk area?

(c) Talk about reinsurance in excess of the Government Reinsurance level is specious, since it is liable to be too expensive, if not completely unavailable. 
(d) What are these "sound insurance principles" which will be used to calculate the reinsurance premium for the Government Reinsurance and the "premiums taking into account risk differences" for the Pool ? Statistical Theory? Hardly, because while statistical theory can sometimes be used to estimate past parameters it cannot be used to predict the future. These sound insurance principles sound like more sophisticated calculations based on simple false assumptions and spurious measurement.

(e) Finally, the role of Government in providing "national emergency" disaster insurance is recognised, but it is not developed in any detail. The funding of this assistance on an ad hoc basis etc., agrees with the General Insurance Bulletin proposals. But the fact that the level of this assistance is not predetermined seems to be a most serious drawback. The insurance cover could well be inadequate.

It is interesting that all these proposals and criticisms are based on general reasoning and do not rely on mathematical or statistical analysis. It is an illustration of the importance of simple ideas.

\section{Conclusions}

\section{Forecasting}

As with all other forms of insurance it is not possible to make reliable forecasts of natural disasters. But whereas forecasts are a useful though unreliable device for normal insurance they are particularly unreliable for natural disasters.

\section{Rating}

There are two aspects of rating for disaster insurance, i.e. rate relativities and overall income. Rate relativities will depend on the capacity and willingness of people to pay; on social justice arguments-and will depend very little on statistical differences. Overall income will inevitably be inadequate because people are only willing to pay for a major disaster after it has happened.

\section{Insuring}

An ordinary insurance company, no matter how large it is, must think very carefully before it touches Natural Disaster Insurance. You have simply got to have a guarantee that losses will be recovered-or a loophole to get you off the hook of a massive claim. 


\section{REFERENCES}

[I] Heller, R., The Naked Manager. This chatty little book is a mine of stimulating ideas on management and its myths.

[2] These simple ideas are discussed in more detail in - RYDER, J. M. The Simple Minded Actuary-1976, General Insurance Bulletin No. 5. (An informal publication circulated in Australia).

[3] The attack on Risk Theory is developed in-Ryder, J. M., Subjectivism - A Reply in Defence of Classical Actuarial Methods, Part III (iii). J.I.A. 1976, 103, 59. A general theory for the adaptive control of insurance processes is discussed in-RYDER, J. M., A General Theory of Insurance, 1976, General Insurance Bulletin No. 6.

[4] e.g. "The claim is often made that we "derive" estimates of probabilities-that is predictions of frequencies--from past occurrences which have been classified and counted (e.g. mortality statistics). But from the logical point of view there is no justification of this claim. We lave made no logical derivation at all. What we may have done is to advance a non-verifiable hypothesis which nothing can ever justify logically: the conjecture that frequencies will remain constant and so permit extrapolation". - Popper, K. R., The Logic of Scientific I)iscovery, Hutchinson; London, I968.

[5] Seal, H. L., Stochastic Theory of a Risk Business, John Wiley and Sons I969.

[6] Almer, B., Modern General Risk Theory, A.S.T.I.N. 1967, IV, I36.

[7] "Earthquakes" Munich Re, 1973.

[8] Buchanan R. A., and others, A Natural Disaster Scheme for Australia, I967, General Insurance Bulletin No. 7 . 